\section{Quando, como e o que se bebe: o processo de alcoolização entre populações indígenas do alto Rio Negro, Brasil}

\author{
When, how, and what to drink: alcoholism among \\ Indian peoples in the Upper Rio Negro, Brazil
}

Maximiliano Loiola Ponte de Souza ${ }^{1}$

Luiza Garnelo 1,2

\section{Introdução}

This paper analyzes the development of alcoholism among Indian peoples in the Upper Rio Negro, Amazonas State, Brazil. Based on a comprehensive approach to what, how, and when individuals drink, this ethnography emphasizes the socio-cultural and historical context in which alcohol is consumed and interpretation of the issue by Indian people themselves. The article discusses historical transformations in the forms of drinking and their correlations with the status quo and changes in social standards of living. The article concludes that current forms of alcohol consumption are linked to the behaviors and values emerging on the frontier of interethnic relations and the resignification of the traditional culture, currently experiencing difficulties in offering parameters for action and symbolization of social life by the younger generations as they deal with challenges from the modern world.

Alcohol Drinking; South American Indians; Behavior
Uma das principais colaborações da antropologia ao tomar como objeto de estudo a questão do uso de bebidas alcoólicas foi demonstrar a variabilidade cultural das formas de beber 1, permitindo o questionamento de conceitos, modelos e teorias que interpretam o fenômeno como um invariante universal 2 .

Um dos conceitos criticados é o de alcoolismo, sobretudo quando entendido como uma doença crônica, fatal, progressiva e com apresentação similar em qualquer contexto social 3,4 . Ao restringir as pesquisas à dimensão do alcoolismo-doença, deixa-se de investigar outros aspectos importantes relacionados ao uso de álcool.

Menendez 5 aponta a necessidade de se investigar o papel do consumo de álcool em culturas específicas. Para isso, o autor propõe o conceito de alcoolização, que seria “...o conjunto de funções e conseqüências positivas e negativas que cumpre a ingesta de álcool para conjuntos sociais estratificados e não apenas, o estudo dos alcoólicos dependentes, nem os excessivos, nem os moderados, nem os abstêmios, mas sim o processo que inclui a todos e que evita considerar o problema em termos de saúde elou enfermidade mental" 5 (p. 63). Tal conceito gera a necessidade de contextualizar o uso de álcool, na cultura e na história, e não apenas o uso problemático. Em última análise, busca o significado que o beber 
assume para um dado grupo social, em um determinado tempo.

Investigando essa temática entre populações indígenas, Langdon ${ }^{6}$ (p. 86) acentua a idéia de variabilidade, ao afirmar que " a maneira de beber, como beber e quanto beber nas culturas indígenas têm sido definidos pela etnia específica, e o consumo de bebidas fermentadas é uma manifestação das atividades constitutivas para o grupo social, expressando sensações e valores particulares".

O objetivo deste texto é analisar o processo de alcoolização entre populações indígenas do Alto Rio Negro, noroeste amazônico, demonstrando a inter-relação entre o contexto sócio-cultural local, a história das relações interétnicas e os modos de consumo de bebidas alcoólicas. A pesquisa se preocupou com o que se bebe, como se bebe e quando se bebe ${ }^{6}$, efetuando uma abordagem interessada em apreender as modificações e ressignificações associadas ao beber, a partir do ponto de vista nativo.

\section{Contexto cultural}

O Alto Rio Negro é habitado por indígenas pertencentes aos troncos lingüísticos Tukáno, Aruák e Makú. Embora exista diferença entre eles, compartilham "o cultivo da mandioca amarga; o consumo de caxiri (bebida alcoólica produzida a partir de mandioca); as festas de trocas (dabucuris) e os rituais de iniciação masculina com o uso de flautas sagradas" 7 (p. 5).

As atividades rituais habitualmente estão associadas ao consumo de bebidas alcoólicas. $\mathrm{Na}$ cosmologia desses grupos a origem do mundo está ligada ao consumo de caxiri e de tabaco pelos deuses primordiais. A literatura etnológica sobre a região atesta a ampla associação entre o consumo de bebidas alcoólicas, o acesso a estados alterados de consciência, o contato com o sagrado e a reprodução destas sociedades 7,8,9.

A confecção do caxiri é uma atividade feminina cujo preparo leva de dois a três dias ${ }^{9}$. Tradicionalmente ele é consumido coletivamente nas festas de troca, que permitem o estreitamento de alianças políticas e matrimoniais entre os diferentes grupos e o intercâmbio de gêneros alimentícios em um ambiente carente de recursos 10. Igualmente a bebida costuma ser consumida durante a realização de trabalhos coletivos, nos quais os laços de solidariedade e obrigações mútuas são reforçados. Em tempos passados as festas duravam dias e, como atualmente, a festa termina quando a bebida se esgota.

O contato interétnico, iniciado há mais de três séculos, propiciou a introdução da cachaça, que foi ativamente utilizada pelos colonizadores como meio de escravização 11. Além da cachaça, outras substâncias, como o álcool de farmácia, desodorante e perfume passaram a ser ingeridos. Outra situação associada ao contato foi a introdução da educação formal pelos missionários. A implantação de escolas nos povoados trouxe importantes mudanças na organização dessas sociedades indígenas, tais como a concentração das famílias, antes dispersas, em locais próximos às aldeias com escolas. Tal mudança parece se associar ao incremento das situações em que se bebe, visto que amplia a quantidade de trabalhos coletivos e das festas e favorece a mobilidade social, em contraste com as tradicionais relações de hierarquia que ancestralmente regem o ethos rionegrino.

\section{Metodologia}

O recorte etnográfico da pesquisa pauta-se pela abordagem interpretativa de Geertz 12,13. Esse autor propõe a existência de uma íntima interação entre cultura e organização social e define a cultura como um padrão de significados, produzidos e transformados historicamente pelos homens, emergindo da interação social e variando segundo o contexto em que são engendrados. A noção de cultura como um sistema fluido e aberto à reinterpretação, subsidiou o desenho de pesquisa, conduzindo à idéia de que os sentidos atribuídos ao beber só poderiam ser apreendidos através do entendimento das condições ancestrais e atuais da vida indígena e de suas mudanças, produzidas por sujeitos que partilham uma teia específica de significados. Subsidiariamente as contribuições de Langdon 6 , Menendez 5 e da literatura etnológica sobre o Alto Rio Negro 7,8,9,10,11 também moldaram as estratégias de coleta e análise dos dados.

Os dados desta pesquisa fazem parte de um projeto de pesquisa mais amplo, que investiga as relações entre saúde, cultura e condições de vida dos grupos indígenas rionegrinos. Os autores têm uma história prévia de interação com esses grupos, que abrange, no caso da autora, um período de 17 anos. Os dados de campo que tratam do tema específico da alcoolização foram coletados em três aldeias diferentes, cujos nomes são omitidos para se evitar a estigmatização dos indígenas que lá residem. As aldeias foram selecionadas por apresentarem condições favoráveis à pesquisa, tais como o bilingüismo (Português e Tukáno); a co-habitação de vários grupos étnicos agrupados em torno das escolas e das igrejas; o difícil acesso; a longa distância do centro urbano mais próximo (São Gabriel da Cachoeira) e o fácil contato com comerciantes, os fornecedores privilegiados de bebidas alcoólicas industriali- 
zadas. Além disso, ainda que não existam dados epidemiológicos prévios sobre a magnitude do problema do uso abusivo do álcool no Alto Rio Negro, esses assentamentos são reconhecidos pelos agentes políticos indígenas como locais em que a alcoolização é intensa, freqüente, violenta e prejudica o desenvolvimento de atividades rotineiras de subsistência.

A complexidade do objeto exigiu a associação de técnicas de pesquisa 14,15 , tais como a observação participante, a coleta de entrevistas semiestruturadas, de entrevistas em profundidade e a realização de grupos focais com jovens de 14 a 18 anos.

\section{Resultados e discussão}

\section{O que se bebe e como se bebe}

Nos locais pesquisados, o caxiri permanece sendo a bebida mais consumida. Seu preparo atual difere da forma como era ancestralmente produzido, pois a indução da fermentação pela saliva das mulheres foi substituída pelo acréscimo de açúcar e aquecimento ao fogo. Segundo os informantes, essa forma de preparação produz uma bebida com maior teor alcoólico.

Tal como ocorre entre outras culturas indígenas 6 , uma vez preparado, o caxiri é consumido até seu término, sendo este o principal mecanismo regulador da quantidade de bebida ingerida. Caso a bebida preparada não seja consumida no mesmo dia, será na manhã seguinte, não se praticando a estocagem da mesma.

A cachaça aparece como a segunda bebida mais consumida. Outras bebidas contendo álcool são utilizadas, tais como o álcool de farmácia, desodorante e perfume, entretanto, o seu consumo é visto como inadequado pela população.

A lógica de consumo do caxiri até o seu término foi transposta para a cachaça, "bebe até terminar a grade [de cachaça]. E não querem parar mesmo não. Sempre vão tomando; continua tomando mesmo no dia seguinte. Até terminar a grade. Aí, só quando terminam as grades, eles começam a parar" (Masculino, Tukáno, 35 anos).

Ao se discutir o uso da cachaça, era comum ouvir os entrevistados dizerem que desde o início da colonização a bebida foi trazida pelos brancos que navegam pelos rios da região. Ilustrativo desse fato é o relato de como, pela primeira vez, um indígena fez uso dessa bebida em uma das aldeias investigadas, na década de 1960.

"Falaram que o comerciante ia passar aquele barco grande, para cima da cachoeira. Ele convidou todo o pessoal para ajudar. Então chegamos lá no fim da cachoeira, então ele disse: 'olha, quem quer bolacha, faz fila aqui; quem quer bombom, faz fila aqui; agora, quem quer cachaça, faça fila aqui'. Eu fui fazer fila na de bebida, sabe. Doido para experimentar o que era. Ele dava dois pacotes de bolacha, para os outros bombons, e para nós um pouco de cachaça. Aí ele disse: 'quem quer mais, faz fila de novo'. Ele passou lá em cima, depois voltou, e já marcou a data que já ia passar por aí de novo. Aí, a gente esperava" (Masculino, Desáno, 60 anos).

A narrativa desse informante atesta uma prática que se perpetua em tempos mais recentes. A cachaça antes utilizada como meio de subjugação e aliciamento para o trabalho forçado 11 , passa a ser uma das moedas de troca de trabalho indígena por produtos manufaturados, hoje imprescindíveis à sua subsistência.

Embora a cachaça tenha sua entrada nas áreas indígenas proibida pelo Estatuto do Índio (Lei $n^{o} .6001$, de 19 de dezembro de 1973) 16, isto não impede a circulação clandestina, ainda que por preços exorbitantes. Se na sede do Município de São Gabriel da Cachoeira a garrafa de $600 \mathrm{ml}$ pode ser comprada por três Reais, nas aldeias ela adquire valores superiores a vinte Reais, tornando seu consumo um símbolo de prestígio e um objeto de desejo.

"Hoje é status beber cachaça porque você vai comprar uma bebida de vinte, trinta, quarenta, cinqüenta Reais à noite" (Masculino, Tukáno, 49 anos).

A aquisição da bebida pode ser feita em dinheiro vivo, ou, em menor escala, trocada por farinha, peixe ou gêneros da floresta. Em conseqüência, as pessoas que possuem trabalho remunerado (professores, agentes de saúde, aposentados e militares indígenas) são os que têm maior acesso, embora seu consumo não se restrinja aos compradores. Sendo um produto associado ao prestígio, os que adquirem a bebida são pressionados a partilhá-la com os demais, demonstrando sua generosidade e inserindo o consumo de bebida alcoólica no grande conjunto de relações de reciprocidades que fundamentam o modo de viver indígena.

\section{Início do consumo de bebidas alcoólicas}

O estudo da idade de início do uso de caxiri deve ser correlacionado ao tipo de caxiri: fraco ou forte. O primeiro com baixa fermentação e fraco teor alcoólico, não é considerado uma bebida, mas um alimento consumido a partir da primeira infância (três ou quatro anos). Tal prática não é exclusiva dos índios rionegrinos, sendo compartilhada pelos Kaxináwa, Yamináwa, Kulína e Kaingáng 16. O caxiri forte, considerado bebida, teve o seu consumo inicial descrito pelos infor- 
mantes homens, com mais de 40 anos, por volta dos 12 a 15 anos. O uso nessa faixa etária estava ligado ao ritual de iniciação masculina, atualmente em desuso ${ }^{8}$. As rememorações dos informantes indicam que a idade de início de uso vem caindo sensivelmente nos últimos anos.

Entre as mulheres com mais de 40 anos, o início do consumo se dava, em geral, após os 20 anos, posteriormente ao casamento. Tal comportamento não foi observado entre as informantes jovens, que relatam início de uso mais precoce, assemelhando-se ao padrão masculino atual.

O início do consumo da cachaça, entre aqueles com mais de 40 anos, independentemente do sexo, ocorria após os vinte anos, ou seja, vários anos depois do uso de caxiri. Nos tempos atuais os mais jovens (menos de 20 anos), de ambos os sexos, relatam ter iniciado o uso de cachaça concomitantemente ao de caxiri, ou apenas pouco tempo depois.

A precocidade no início do consumo de bebidas alcoólicas é atribuída pelos informantes da pesquisa ao incremento da movimentação de comerciantes não-indígenas nas últimas décadas, mas a pesquisa mostrou que isto é apenas uma parte do problema, já que os "brancos" não são mais os únicos fornecedores de bebida. $\mathrm{O}$ aumento da navegação dos próprios indígenas e uma crescente relação com o meio urbano, ampliaram a possibilidade de compra em São Gabriel da Cachoeira. Diversos motivos propiciam a ida para a cidade, tais como receber aposentadoria ou salário, comprar mantimentos e visitar parentes ou filhos que lá estudam, potencializando um acesso cotidiano à bebida.

Outra importante mudança no modo de vida está ligada à implantação dos internatos salesianos, entre as décadas de 1950 a 1970, que empreenderam um deliberado esvaziamento da autoridade dos mais velhos sobre os mais novos 17 , seja pela redução do contato intergeracional, seja pela coibição dos ritos de passagem, que representavam uma importante via de internalização dos valores éticos do grupo pelos iniciandos. São eventos que fragilizaram importantes formas de reprodução do acervo cultural, aí se incluindo estratégias de controle de uma geração sobre a outra. A substituição dessas formas de socialização pelas escolas, pouco, ou nada, veio contribuir para a preservação de uma ordem social fundada, em grande medida, na hierarquia das classes de idade.

Embora as escolas das três aldeias não funcionem em regime de internato desde o final da década de 8017 , os estudantes indígenas permanecem distantes de suas famílias, já que os pais continuam residindo na sua localidade de origem e os filhos se deslocam para estudar nos centros missionários, ali ficando aos cuidados de parentes. Muito cedo os jovens ficam expostos à violência e à sedução do contato interétnico e, em conseqüência, a influência das famílias sobre seu comportamento moral fica reduzida às episódicas visitas dos pais ou ao período de férias, quando os jovens retornam para casa. Durante a pesquisa foi possível registrar relatos sobre a embriaguez de garotas menores de 15 anos, aliciadas por comerciantes não-indígenas, que após usarem-nas sexualmente as deixaram desacordadas e abandonadas ao relento. Situações como essa são mais freqüentes no caso de estudantes cujas famílias moram em locais distantes da escola.

Visando a evitar esses problemas, muitas famílias, ou parte delas, deixam suas aldeias para viver no centro missionário na época das aulas. Essa situação traz consigo novas conseqüências negativas, tais como a dificuldade em manter a roça e a pesca para alimentação da família; geram ainda, a ruptura das relações de cooperação com os co-residentes de seu assentamento de origem, e interações conflitivas entre os habitantes originais da localidade e os visitantes semipermanentes, cuja presença provoca disputas por prestígio e bens de subsistência.

Em resumo, os dados mostram que o uso precoce de cachaça pelos jovens está associado, por um lado, a um aumento da oferta e circulação da bebida nas aldeias, e por outro, à dinâmica das relações internas do grupo. O conjunto dessas interações promoveu uma mudança das formas tradicionais de assentamento e de socialização dos jovens, o desgaste da autoridade moral dos velhos e uma impotência das famílias em controlar o uso precoce e abusivo de bebidas alcoólicas industrializadas. Essa interpretação foi corroborada pelos jovens participantes dos grupos focais realizados na pesquisa, que atribuem sua não adesão aos conselhos dos pais, que solicitam moderação no uso de bebidas, a uma fraca autoridade moral de adultos que fazem um uso igualmente abusivo de álcool.

Além disso, os participantes estabelecem uma valoração privilegiada aos "conselhos de antigamente", que eram oferecidos de forma ritualística, com apoio da fumaça de cigarro, permitindo que a orientação "entrasse na cabeça e não saísse". Atualmente essa estratégia teria perdido a eficácia, pois sem o rito propiciatório, "a cabeça fica fechada e os conselhos não entram". Em outras palavras, uma vez abolidos os ritos pubertários, aparentemente não se produziram outras estratégias similarmente eficientes para viabilizar o controle do uso de álcool.

Concomitantemente ao desgaste da autoridade dos mais velhos, observa-se ainda uma reorganização dos critérios definidores de pres- 
tígio, antes associados às hierarquias clânicas e de geração. Os dados obtidos junto aos jovens mostraram que uma de suas principais aspirações é "ter uma vida diferente da dos pais", significando, dentre outras coisas, o desejo de se afastar da produção agrícola e de se tornarem trabalhadores assalariados. A baixa escolaridade, o pouco domínio do português e a inacessibilidade ao trabalho assalariado, tornam os mais velhos um exemplo a não ser seguido. $\mathrm{O}$ acesso à educação formal e ao dinheiro passou a representar importantes objetivos a serem perseguidos, atribuindo-se uma importância menor às fontes tradicionais de prestígio.

As tensões ligadas às disputas por formas novas e velhas de prestígio se expressaram com clareza em situações de embriaguez que se associaram à violência física. Em uma das situações observadas, o conflito instalou-se entre personagens que, pertencentes a clãs desprestigiados, mas detentores de empregos assalariados e de boa escolaridade eram hostilizados por outros indígenas que ocupavam lugares mais prestigiosos na hierarquia ritual tradicional, mas não desfrutavam de um bom acesso às benesses do mundo não-indígena. Da mesma forma, jovens indígenas engajados nas forças armadas, que disputam com vantagem sobre os outros homens os favores sexuais das mulheres disponíveis nas aldeias, tornaram-se objeto de hostilidade dos habitantes da localidade. Pelo menos um caso de séria agressão física pôde ser registrado, num evento em que um militar indígena foi espancado por jovens consangüíneos, sob as vistas e estímulo dos mais velhos.

\section{Quando se bebe}

Os momentos mais comuns de uso de bebidas alcoólicas são as situações de consumo coletivo, tal como ocorre nas festas e na realização de trabalhos comunais; esses são os momentos reconhecidos como culturalmente adequados, segundo a visão nativa. Em tempos anteriores essas situações se restringiam aos contextos rituais específicos e espaçados, porém, as mudanças trazidas pelo contato interétnico introduziram, além dos dabucuri, outras situações festivas no calendário indígena.

A pesquisa identificou 22 datas comemorativas distribuídas ao longo do ano. Destas, 11 estão associadas à Igreja Católica, como as festas de santo. Todas as comunidades possuem seu santo padroeiro; se uma comunidade grande é subdividida em vilas, cada vila terá seu próprio padroeiro multiplicando-se as festas. Outras cinco festas estão associadas às datas do calendário cívico nacional e duas a comemorações escola- res. Em cada uma dessas ocasiões o uso de bebida é considerado um comportamento lícito e aceitável. Além dos momentos supracitados, os informantes referem a existência de outras situações festivas, recentemente introduzidas, tais como os casamentos, batizados e aniversários.

A outra situação de consumo grupal de bebidas alcoólicas se dá na realização de trabalhos coletivos. Estes podem ser divididos em duas categorias principais: os ajuris (realizados por todos, mas no interesse de uma família em particular) e os chamados trabalhos comunitários (realizados pelo grupo, no interesse da coletividade). Tal divisão é relevante nesta análise visto que são contextos de uso de bebidas, nos quais os mecanismos envolvidos no recrutamento para o trabalho são diferenciados, embora tendo ambos implicações na forma de consumo de bebidas alcoólicas.

A chave do entendimento da primeira modalidade de trabalho coletivo remete às antigas malocas, cuja coabitação preferencial se dava entre consangüíneos, que compartilhavam fortes sentimentos de pertença a um grupo de consangüinidade, associados entre si por laços de solidariedade e reciprocidade 8,9,10,11. Embora as malocas também comportassem comensais não-parentes, esta presença era regulada por acordos e obrigações mútuas entre os moradores, incluindo-se o auxílio na realização de trabalhos cotidianos. Após a extinção da maloca, a oferta de comida e bebida persistiu entre os residentes de uma mesma aldeia, ou vizinhos próximos, operando como uma retribuição do grupo beneficiado aos demais participantes do trabalho 11. Um velho resumiu este mecanismo da seguinte forma: "Eu preparo o caxiri aqui, aí eu convido meus filhos, meu tio, meu sobrinho, meu neto, meu cunhado, esses são assim [parente] para mim. Porque o campo é grande. Aí eu não posso roçar sozinho" (Masculino, Tukáno, 73 anos).

Porém, nos povoados que se formaram em torno das missões ocorreu uma mudança no padrão de assentamento - e em conseqüência, nas obrigações mútuas - incentivando-se a co-residência de não-parentes; nos dias de hoje não é incomum que rivais e desafetos passem a habitar na mesma localidade. Na organização atual do ajuri, a oferta de bebidas substitui, em parte, a motivação decorrente dos antigos laços de solidariedade entre parentes, como se pode apreender do discurso do supracitado informante.

"Porque antigamente, às vezes trabalhava para o parente, só por farinhazinha, comida. Era parente (...) Agora não. (...) Quando não tem caxiri, quase não vai não. Vão três, cinco. Agora quando tem, pronto! Todo mundo quer tomar; aí vai 
embora, rapazes, velho, moças, mulher às vezes" (Masculino, Tukáno, 73 anos).

Assim, a bebida vem se tornando a principal forma de retribuição pelo trabalho comunal, inflada artificialmente pelos novos padrões de assentamento que divergem da clássica patrilocalidade rionegrina.

Por outro lado, houve um incremento das situações em que se promove ajuri, estando tal fato associado à existência de indígenas cuja atividade principal é remunerada (professores, por exemplo). Por indisponibilidade de tempo para o trabalho na roça, esses assalariados tendem a promover os ajuris com freqüência. Soma-se a isso, o alto prestígio auferido pelos donos de grandes roças, gerando a paradoxal situação em que os assalariados, com status mais alto e com menos tempo para o trabalho agrícola, são os que tendem a ter uma maior quantidade de roças. É uma situação que demanda um alto investimento na promoção de ajuris e, conseqüentemente, uma maior distribuição de bebida alcoólica.

Já os trabalhos comunitários podem ser realizados com vários propósitos. Outrora a construção de uma maloca ou manutenção das armadilhas de pesca demandava uma negociação delicada envolvendo o líder da aldeia e os demais indígenas, visto que as chefias locais não tinham (como ainda hoje não têm) poder de mando sobre os demais membros do grupo 9,10. O tuxaua exercia a chefia em bases de prestígio, fundado na sua posição na hierarquia ritual, no acesso privilegiado aos recursos pesqueiros e na generosa distribuição dos bens por ele auferidos 10 .

Esse sistema de chefatura foi alterado sob a ação salesiana que fragmentou as atribuições dos chefes, e manipulou a escolha de lideranças segundo critérios que favorecessem o poder missionário 10,11. As novas chefias não detêm as prerrogativas do antigo líder, entretanto continuam a precisar do trabalho coletivo dos demais, para manter certas atividades necessárias à sobrevivência de todos. Também é fato que houve um incremento das situações que exigem a realização desses trabalhos. Na atualidade, os trabalhos comunitários são rotineiramente promovidos para executar políticas públicas que não se interiorizam nas aldeias, tais como a reforma da escola, a limpeza da comunidade, a instalação de rede elétrica e outros.

Nesse contexto de frágil legitimidade política, a oferta de bebida alcoólica pela liderança surge como um elemento fundamental para a adesão do grupo aos trabalhos comunitários. A associação entre trabalho comunitário e consumo de bebida é criticada por aqueles que discordam que a liderança lance mão da bebida para mobilizar a comunidade para o trabalho.
"Eu estou vendo assim, aqui na aldeia tem capitão que costuma, no dia de comunidade, fazer roça grande. Ele costuma mandar preparar caxiri. Todo mundo junto: pronto, vamos plantar. O chefe é que está estragando, prepara todo tempo caxiri. Porque antigamente não era assim" (Masculino, Tukáno, 73 anos).

O informante se referia a um trabalho coletivo, que tinha por objetivo a preparação de uma grande roça comunitária destinada às pessoas que não residiam na aldeia, mas que lá permaneceriam parte do ano para acompanhar os filhos na escola. Tal trabalho difere do que costuma ser chamado de ajuri, pois não era um trabalho coletivo promovido por uma família específica, com a colaboração dos demais. Também não era um trabalho comunitário, visto que não seriam beneficiados todos os membros da comunidade. Tal roça coletiva é uma inovação trazida pela escolarização massiva, congregando o esforço de pessoas com frouxos laços entre si. Conforme se previu, sua realização só foi viabilizada por meio de grande oferta e consumo de caxiri.

Como já assinalado, o consumo de álcool não se dá exclusivamente nas situações de festas e de trabalhos coletivos. Em uma das aldeias, o uso de álcool fora do contexto coletivo é incrementado pela atividade constante de barcos de comércio. Durante a pesquisa observamos o recrutamento de jovens para realizar o carregamento e transporte de mercadorias para transpor a grande cachoeira que existe no local. Esse recrutamento, realizado por comerciante não-indígena, foi feito de modo individualizado, sem a menor interferência do capitão da comunidade. A cachaça foi o estímulo para o recrutamento e a forma de pagamento do trabalho. O consumo subseqüente foi meramente recreativo, microgrupal, restrito aos jovens trabalhadores, e não no ambiente coletivo ligado aos rituais de reprodução da sociedade. Em circunstâncias como essa se observa mais comumente o uso de substâncias consideradas como impróprias para o consumo, como álcool de farmácia, desodorante ou perfume.

Em situação similar, noutra localidade investigada, uma sala da escola foi arrombada e uma garrafa de álcool foi roubada. De acordo com uma informante, “(...) ao terminar a festa, às vezes, os jovens procuram até acharem álcool por aí e fazem batida" (Feminino, Desáno, 22 anos).

$\mathrm{O}$ antigo hábito de beber, até que se acabe o estoque de bebida, permanece. Antigamente esse costume operava como regulador do consumo abusivo, pois limitava a bebedeira à quantidade de bebida disponível, obrigando a uma pausa no consumo até um novo momento ritual. Tal forma de controle está sendo inviabilizada pela presença constante de substâncias alcoólicas, 
no dia-a-dia das comunidades. Assim, o término do caxiri não demarca mais o encerramento do consumo, mas ao contrário, pode desencadear uma frenética procura por álcool, de qualquer espécie, para dar continuidade a um consumo, agora microgrupal.

\section{Considerações finais}

O cenário encontrado pode ser descrito como um fruto de permanências e mudanças simbólicas e materiais dessas sociedades, geradas ao longo de três séculos de contato com a sociedade nacional. Os símbolos e significados que expressam o processo de alcoolização descrito indicam que, nos locais estudados, os recursos tradicionais de ordenação da vida indígena parecem estar em xeque, enfrentando dificuldade em exprimir a experiência social atual e oferecer parâmetros de ação para as gerações mais jovens, que demandam novas formas de orientação de comportamentos e de valores frente ao mundo contemporâneo.

Os quase sessenta anos de abolição dos ritos de passagem parecem cobrar seu preço, propiciando a contestação da estrutura hierárquica tradicional que regulava minuciosamente as interações entre os diferentes nichos sociais e minimizava conflitos e violência entre gerações. Mudanças trazidas pela escolarização e assalariamento, pelo domínio da língua portuguesa e da etiqueta política que hoje rege o exercício da etnicidade, geraram um tipo de protagonismo político indígena que é exercido através de competências técnicas, políticas e econômicas, distintas dos laços de parentesco, que outrora regiam o sistema de prestígio frátrico e os comportamentos chancelados pelo grupo. A busca de modos urbanos de vida e o afastamento deliberado dos comportamentos e da moral tradicional parecem contribuir para uma carência de parâmetros de orientação do comportamento das novas gerações frente ao consumo de álcool.

As informações geradas pela investigação não podem ser extrapoladas para o conjunto de sociedades rionegrinas, mas para os locais pesquisados consideramos que a alcoolização abusiva expressa um mal-estar ligado a uma indefinição sobre o modo adequado de conduzir a socialização das novas gerações. Os dados também sugerem a existência de um processo, ainda pouco delineado, de construção de novas formas de socialização. Em seu processo de consolidação elas deixam o caminho aberto para a ambigüidade e a violência, antes obscurecidas pela ritualização da hierarquia.
As alterações no consumo de álcool foram marcadas pelas mudanças na forma de preparo da bebida, pelo incremento das situações consideradas adequadas para beber e, principalmente, pelas mudanças no contexto histórico. Frente a estas, o grupo lançou mão de regras de conduta previamente existentes, redimensionando-as e ressignificando-as para fazer frente às novas realidades que se lhes apresentavam. Se por um lado, o grupo incorporou as mudanças de contexto adotando novas atitudes, até o momento atual parecem não ter forjado meios eficientes de regulação do uso de álcool no mundo contemporâneo. A principal estratégia de limitação do consumo permanece sendo a não disponibilidade da bebida; porém, o uso desse controle externo para limitar o embebedamento se mostra incapaz de produzir resultados eficientes, dados o incremento da movimentação indígena e o acesso a um número progressivamente maior de transportes eficientes e velozes.

Tornado um símbolo de status, que confere distinção àquele que a adquire e a redistribui, o uso da cachaça se integrou aos mecanismos tradicionais de generosidade e reciprocidade que regem a circulação dos bens, sendo limitado apenas pela indisponibilidade de recursos para adquiri-la. É algo que torna os assalariados, independente de sua posição na hierarquia tradicional, um alvo preferencial de críticas a um comportamento mesquinho - particularmente nos momentos de embriaguez coletiva, quando as acusações podem redundar em violência física - e tende a incrementar a distribuição da bebida.

Outro elemento de mudança cultural que amalgama comportamento tradicional e influência do contato interétnico é a alcoolização do trabalho, ampliada pelo incremento das situações que exigem a mobilização coletiva para urbanizar aldeias cada vez maiores; tal tarefa fica ainda mais dificultada pela progressiva fragmentação da autoridade das chefias locais. Nesse cenário, a oferta sistemática de bebida passou a operar como estratégia de recrutamento de mão-de-obra, não para atender aos patrões brancos, mas para reproduzir o modo atual de vida indígena.

Em conjunto essas reflexões corroboram a idéia da dinâmica da cultura, onde a dicotomia entre tradição e mudança não se sustenta. Assim, o processo de alcoolização deve ser aqui concebido como resultado da coexistência de normas sociais e padrões de ação antigos e contemporâneos; ela modula a configuração dos contextos de uso do álcool e permite, de formas diversas, e freqüentemente conflitivas, atribuir sentido aos desafios que se apresentam na existência desses povos, empenhados em constante reelaboração de seu viver cotidiano. 
Sem ter a pretensão de extrapolar os achados rionegrinos para o complexo panorama das diversas sociedades indígenas que vivem no Brasil, consideramos que a situação ali encontrada permite refletir sobre os graves problemas hoje enfrentados pelas sociedades indígenas no tocante a essa questão. Nos locais investigados os dados mostraram que as antigas formas de regulação dos conflitos sociais não se mostram capazes de enfrentar as novas faces assumidas pelo consumo do álcool.

Por outro lado, as únicas soluções até agora aventadas, apontam para o incremento da fiscalização das embarcações pela Fundação Nacional do Índio (FUNAI). Em vigor há muitas décadas, essas medidas repressivas não lograram qualquer eficácia para o controle do tráfico de bebidas alcoólicas; o problema se exacerba nos dias de hoje, em que há indígenas que desenvolvem atividades comerciais, entre as quais se inclui a venda de bebidas alcoólicas. Nesse caso, as medidas de fiscalização - concebidas sob o pressuposto de que a movimentação de álcool nas terras indígenas seria produto exclusivo da ação dos não-indígenas - teriam de incidir sobre as embarcações indígenas, ferindo seu direito inalienável de ir e vir em suas próprias terras, adicionando mais um componente de tensão nas relações entre os indígenas e o órgão indigenista, reduzindo quaisquer chances de sucesso.

No intrincado leque de interações que envolvem o uso do álcool, podemos nos perguntar o que os indígenas pensam sobre o assunto, e que medidas proporiam para buscar soluções para o problema em seus próprios territórios. No caso rionegrino o desconforto indígena é evidente e suas lideranças vêm discutindo o tema. Dentre as medidas já encaminhadas, situamos a pesquisa que produziu o presente artigo, que foi, originalmente, concebida para atender a uma demanda das associações indígenas locais, desejosas de entender a nuance do problema. Os produtos da pesquisa foram discutidos em assembléias indígenas, tendo as lideranças percebido que, longe de ser um problema médico, o consumo de álcool está a exigir uma reestruturação de suas próprias relações familiares, e um debruçar-se sobre os rumos que desejam imprimir no futuro de suas gerações mais jovens. Ainda assim, no Alto Rio Negro, o debate permanece aberto, sem que se tenha, ainda, logrado um curso consensual de ação.

\section{Resumo}

O texto analisa o processo de alcoolização em populações indígenas do Alto Rio Negro, Amazonas, Brasil. Baseando-se num enfoque compreensivo sobre o que se bebe, como se bebe e quando se bebe, a etnografia privilegia o estudo do contexto sócio-cultural e histórico no qual se dá o consumo de álcool e a interpretação nativa sobre a questão; discute as transformações históricas nas formas de beber e suas correlações com as permanências e mudanças da vida social. Conclui que as formas atuais de consumo de álcool estão ligadas à adoção de comportamentos e valores engendrados na fronteira das relações interétnicas e às ressignificações da cultura tradicional que hoje enfrenta dificuldade para oferecer parâmetros para a ação e para a simbolização da vida social pelas gerações mais jovens, frente aos desafios do mundo contemporâneo.

Consumo de Bebidas Alcoólicas; Índios Sul-Americanso; Comportamento

\section{Colaboradores}

M. L. P. Souza participou das etapas de revisão da literatura, coleta de dados, análise de resultados, redação do texto. L. Garnelo participou de todas as etapas, com exceção da coleta de dados. 


\section{Referências}

1. Heath DB. Cross-cultural studies of alcohol use. Recent Dev Alcohol 1984; 2:405-15.

2. Heath DB. Recent developments in alcoholism: anthropology. Recent Dev Alcohol 1993; 11:29-43.

3. Kunitz SJ, Levy JE. Drinking careers: a twentyfive-year study of three Navajo populations. New Haven/London: Yale University Press; 1994.

4. Neves DP. Alcoolismo: acusação ou diagnóstico? Cad Saúde Pública 2004; 20:7-36.

5. Menendez EL. El proceso de alcoholización: revisión crítica de la producción socioantropológica, histórica y biomédica en América Latina. Cuaderno de la Casa Chata 1982; 57:61-94.

6. Langdon EJ. O que beber, como beber e quando beber: o contexto sociocultural no alcoolismo entre as populações indígenas. In: Seminário sobre alcoolismo e DST/AIDS entre os povos indígenas. Brasília: Coordenação Nacional de DST e AIDS, Secretaria de Políticas de Saúde, Ministério da Saúde; 2001. p. 83-97.

7. Buchillet D. Los poderes del hablar. Terapia y agresión chamánica entre los indios Desana del Vaupes brasileño. In: Basso E, Sherzer J, organizadores. Las culturas nativas latinoamericanas a través de su discurso. Quito: Abya-Yala/MCAL, 1990.

8. Reichel-Dalmatoff G. Dessana: simbolismo de los indios Tukano del Vaupes. 2a Ed. Bogotá: Procultura; 1986.

9. Jackson JE. The fish people: linguistic exomamy and Tukanoan identity in Northwest Amazon. London: Cambridge University Press; 1983.
10. Chernela JM. The Wanano Indians of the Brazilian Amazon: a sense of Space. Austin: University of Texas Press; 1993.

11. Oliveira AG. O mundo transformado: um estudo da "cultura de fronteira" no Alto Rio Negro. Belém: Museu Paraense Emílio Goeldi; 1995.

12. Geertz C. A interpretação das culturas. Rio de Janeiro: Livros Técnicos e Científicos Editora; 1989.

13. Geertz C. O saber local. 5a Ed. Petrópolis: Editora Vozes; 2002.

14. Deslandes SF, Gomes R. A pesquisa qualitativa nos serviços de saúde: notas teóricas. In: Bosi MLM, Mercado FJ, organizadores. Pesquisa qualitativa de serviços de saúde. Petrópolis: Editora Vozes; 2004. p. 99-120.

15. Minayo MCS. O desafio do conhecimento: pesquisa qualitativa em saúde. 8a Ed. São Paulo: Editora Hucitec; 2004.

16. Oliveira M. Uso de bebidas alcoólicas e alcoolismo entre os Kaingang da bacia do Rio Tibagi: uma proposta de intervenção. In: Jeolas LS, Oliveira M, organizadores. Anais do Seminário Cultura, Saúde e Doença. Londrina: Secretaria Municipal de Saúde de Londrina; 2003. p. 43-65.

17. Federação das Organizações Indígenas do Rio Negro/Instituto Socioambiental. Povos indígenas do Alto e Médio Rio Negro: uma introdução à diversidade cultural e ambiental do noroeste da Amazônia. 2a Ed. São Gabriel da Cachoeira: Federação das Organizações Indígenas do Rio Negro/Instituto Socioambiental; 2000.

Recebido em 09/Mar/2006

Versão final reapresentada em 29/Jan/2007 Aprovado em 06/Fev/2007 